\title{
Portuguese Universities Sharing Remote Laboratories
}

\author{
doi:10.3991/ijoe.v5s2.1090 \\ M.T. Restivo ${ }^{1}$ and M.G. Silva ${ }^{2}$ \\ ${ }^{1}$ University of Porto, Porto, Portugal \\ ${ }^{2}$ University of Coimbra, Coimbra, Portugal
}

\begin{abstract}
This paper describes a pedagogical assignment based on a cooperative work involving teachers/students from two Portuguese universities. As it happens one is the oldest in the country - University of Coimbra (UC) - and the other the largest - University of Porto (UP), about 120 km apart.
\end{abstract}

The authors, believing in the relevance of Information and Communication Technologies (ITs) in teaching/learning methodologies and in cooperative teaching methods worked together to plan this pedagogical experience and to run it in a one semester course.

Students from UC have been introduced to the remote lab at UP and got the first contact with the remote experiments using easily available sound and image resources based on Skype and an IP camera for better image quality. This first contact has been conducted by the first author at UP with support of the second author at UC.

The work will describe briefly the remote experiments used, their inclusion in the course at UC, the associated assessment criteria and, finally, student comments.

Index Terms-Remote and virtual laboratories, on-line labs, collaborative teaching.

\section{INTRODUCTION}

This paper depicts a pedagogical assignment based on cooperative work involving teachers/students from two Portuguese universities: one is the oldest in the country University of Coimbra (UC) - and the other the largest University of Porto (UP), about $120 \mathrm{~km}$ apart.

The idea of creating this pedagogical experience came from the Mechanical Engineering Departments of Faculdade de Ciências e Tecnologia da Universidade de Coimbra (FCTUC) and of Faculdade de Engenharia da Universidade do Porto (FEUP).

At FEUP, a two-year Project "Experimenta@FEUP" (2006/2008), [1], has been strongly devoted to promote the use of ITs in the teaching/learning environment, with particular emphasis on the development of remote and virtual laboratories for widening the availability of experimental tools, contributing in this way to increase the so important experimental component in the learning process [2], [3] and [4]. It also aimed to establish links with other higher education institutions in the promotion of experimental tools in engineering education. The Laboratory of Instrumentation for Measurement (LIM) at FEUP has been actively involved in this project, promoting the use of ITs in the classroom, namely by the use of remote and virtual laboratories as well as by developing elearning courses [5]. LIM is mainly committed to system sensorization, measurement and metrological procedures, system automation, monitoring and data transmission. So, all the remote and virtual experiments conceived and developed at LIM are oriented within these fields.

The next section will briefly describe the involvement of LIM in the setups used as remote laboratories in the present work, among all the resources available at the address http://eLabs.fe.up.pt.

At FCTUC there is a 6 ECTS Measurement and Instrumentation course in the second year of Mechanical Engineering, where the students, besides the explanatory lectures and the resolution of problems, have to do some experimental laboratory work consisting mainly in the measurement of physical quantities important to the mechanical engineering area. In this course there was already a tradition of resorting to the means offered by modern ITs to facilitate the transmission of knowledge, namely through the use of virtual laboratories that are available to the students, [6], [7], [8] and [9].

\section{EXPLORED REMOTE LABS@FEUP}

The more obvious way of starting the collaboration between the two universities was to make available to FCTUC students remote access, through the internet, to the experiences already installed and running at FEUP. The process started with an introductory lecture in which the existing experiences were described and shown to the students in the classroom at FCTUC through a virtual visit done by Skype for sound and by video connection through a 2-axis moving IP camera mounted in the laboratory at FEUP. The experiences, the respective data acquisition and control software applications and the booking process were presented and explained in detail during that remote session. After it, written material containing the instructions for booking and accessing the experiences, the description of experiments and the respective theoretical formulation where made available to students through the Web on Campus internet platform at FCTUC. Each student was asked to carry out one of the three selected experiments and, finally, to write a report about it. Considering that all elected remote experiments were dealing with transducers and physical quantity measurement of interest for the course, this final report should substitute a previous assessment component based on a written report relying on sensor issues. The remote access experiment reported weighed $10 \%$ on the final grade of each student. The final grade was calculated with the sum of the grades obtained on two written tests ( $2 \times 6$ on a 20 points scale) and the reports of 3 experimental works $(3+3+2)$, the first two 
carried out at the laboratories at FCTUC and the last one being the remote access experiment. During the period of remote access the students from FCTUC have been free to get help at FEUP, using the first author email whenever they needed. In that sense it was also an interesting interactive experience.

In the next section a short description of the remote experiments as well as their pedagogical scope will be provided.

\section{SHORT TECHNICAL DESCRIPTION AND PEDAGOGICAL SCOPE}

\section{A. Mechanical Material Characterization}

A particular set-up for remotely measuring and determining mechanical material properties is now briefly presented [10]. A cantilever beam instrumented with resistance strain gauges is loaded by a linear motor. In series with the linear motor a miniature load cell is used for measuring the applied load. The system may be used remotely for automatically measuring force, strain and deflection and it may also be actuated in a manual mode for monitoring the cantilever beam system performance for any value of the applied load, within its working range. The application for remote access is developed in LabVIEW 7.1. Fig. 1 shows the user interface available for remote actuation. On the upper right corner a real time video provides real system visualization. Underneath the video window a picture of the overall system offers a realistic perspective of the complete setup.

The future integration of a low cost haptic device with this setup will provide the user with force feedback, supplying a highly realistic actuation of the remote experimental system.

Once an email address is introduced on the remotely accessible user interface the user will get a message with the results at the end of the experiment.

This remote experiment brings the following pedagogical scopes:

- For those students who are familiar with a common hands-on procedure for determining Young modulus using a cantilever beam in a bending test, this system offers a complete automated method through which they may replicate the Young modulus determination of a material using the emailed data sent by the system;

- In this particular case a miniaturized spoked wheel type load cell is used for providing the applied load, in a completely different way from suspending weights at the free end of a cantilever beam;

- Simultaneously, the measured deflection may be compared with the one analytically determined;

- The values found for the Young modulus may present some variability that can be explored;

- The deformed shape along the neutral axis is also displayed during the automated mode, in the right hand side screen, for the three applied load levels;

- Along all this task each student has the chance to develop individual skills for dealing with experimental problems himself, which is generally not the case during real hands-on sessions performed on a workgroup basis of three or four elements;

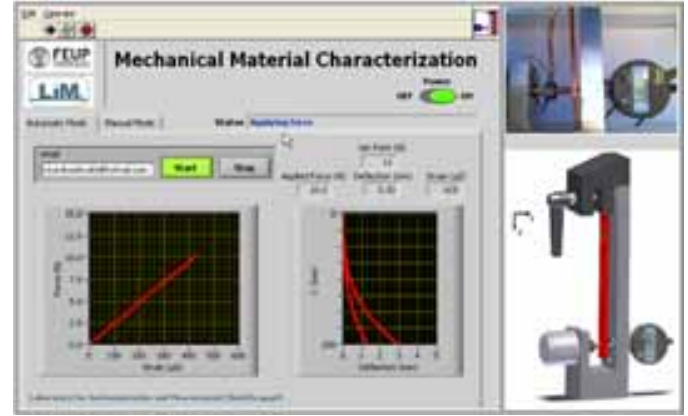

Figure 1. User interface for Mechanical Material Characterization

- The student also becomes familiar with the use of these new technologies;

- A simple upgrade of the set-up (a new measurement bridge and two resistance strain gauges) will make available the evaluation of the Poisson ratio of the material.

\section{B. System for straightness evaluation}

The straightness evaluation system uses a digital gauge moved by a linear motor through a timing belt element, communicating with the PC by an RS232 interface. Two switches, of electromagnetic reed type, are used as security limits for the range measuring length. The software package LabVIEW 7.1, running on a PC with I/O cards, provides remote system supervision and control.

The user may define the range for straightness evaluation along a straight line segment included between the above mentioned limits. He may also define the step value of the digital dial test indicator as well as the number of tests to be performed. Fig. 2 shows the remote user interface, integrating live video from an IP camera.

Once an email address is introduced on the remotely accessible user interface the user will get a message with the experimental data.

This remote experiment includes the following pedagogical scopes:

- The straightness deviation of a given line is a standard and abstract concept and its practical demonstration was never done during the course. So, the system permits the concept materialization by working values returned to the student by the system email functionality incorporated in the application;

- The final objective of the system is to determine the straightness deviation value;

- The system exhibits a totally automated method for performing that measurement;

- Once the number of tests can be chosen by the user, statistical analysis may be carried out;

- The development of individual skills are facilitated;

- The student will become also familiar with the use of these new technologies.

In both experiments a booking system developed at FEUP, as an extension of the Moodle platform, is used for organizing the user remote access to them.

If the user does not arrive within a pre-defined tolerance period, the Moodle extension will free the previously booked time slot. The use of the Moodle platform brings additional advantages for storing tutorials on the subjects. 


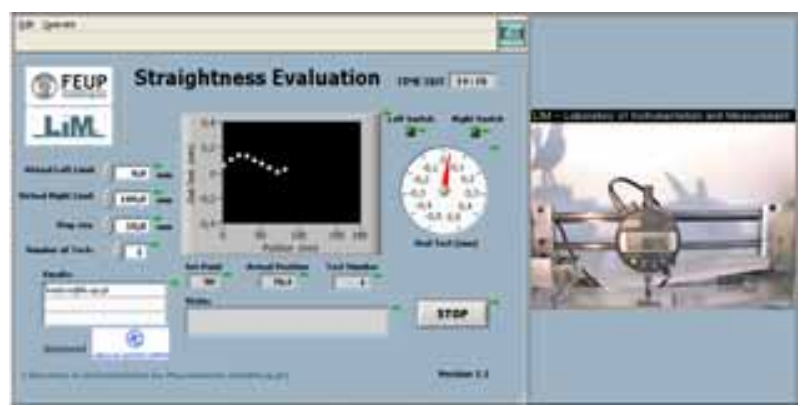

Figure 2. User interface for Straightness Evaluation

\section{Meteorological station at FEUP}

This sensitive remote laboratory aims to contribute to the urban climate characterization of Porto in the station area and for studies related with building characteristics. Several physical quantities (temperature, wind velocity and direction, pressure, relative humidity, radiation intensity and rainfall) within the Campus of FEUP are available every 10 minutes. All the data is recorded in a database for later use by anyone accessing the system. A special IP camera for outdoor use and for night vision is feeding the site, Fig. 3.

This remote experiment of a sensitive type includes the following pedagogical scopes:

- It makes available values of seven different physical quantities, from the common ones as temperature and pressure up to solar intensity radiation, not so familiar;

- Associates to them short descriptions of the working principles for the different sensors/transducers used;

- This station is an example of an urban meteorological station, contributing for the characterization of urban climate at Porto and the recorded values at this location are available for anyone;

- If data is used in connection with some prepared rooms on the surrounding buildings could be useful for determining some thermal characteristics (thermal inertia effects, insulation effectiveness, ...);

- The development of individual skills is facilitated;

- The student will become also familiar with the use of these new technologies.

\section{Authors ThOughts}

The use of remote and virtual laboratories is nowadays discussed in many engineering education contexts [11] and [12]. In the opinion of the authors their use is one complementary solution but not "the solution" for all problems on experimental engineering education.

While being only a complementary solution several broad inherent advantages may be pointed out: they provide bigger mobility and flexibility in lab timetables; they contribute for better resource management; they may contribute for spreading experimental activities; their availability may increase experimental syllabus flexibility by being available everywhere for everyone; as strongly based in the use of ITs, they are a good example of "new technologies in action"; they are promising tools for teaching/learning methodologies and they could also be playing an important role in the lifelong learning process; this complementary tool can help to improve the materiali-

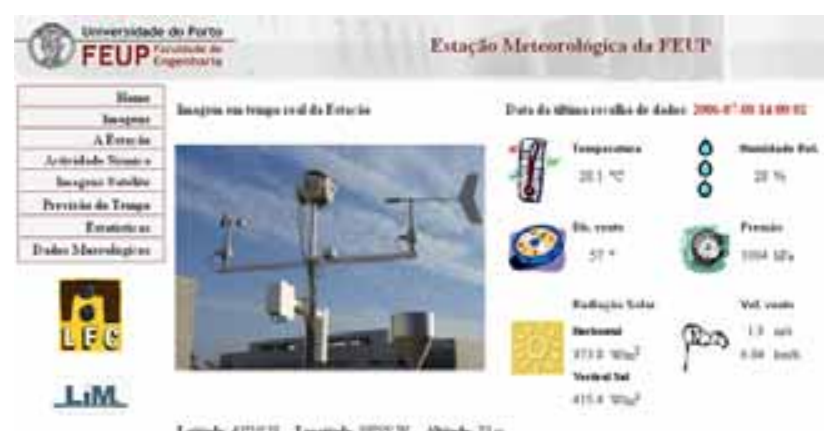

Figure 3. User interface for the Meteorological Station

zation of concepts and contribute to create more flexible contents in course design; the access to a very particular system or to a sophisticated one can be turned into reality with remote technology; finally, the use of remote experiments may improve students' autonomy, in accordance with Bologna philosophy [13].

Meanwhile, FEUP has been committed to the evaluation of the pedagogical efficiency of on-line labs in engineering courses. Staff from the schools of Education Science and Engineering have been working together to attain this goal, the main scope of the project Labs-on-theWeb(http://www.fe.up.pt/si/PROJECTOS_GERAL.MOS TRA_PROJECTO?P_ID=1105). An inquiry including 26 different items has been designed. The authors of this work have selected ten of them considered relevant to the specific aspects related with the use of remote experiments and results are presented in the following section.

\section{STUDENT COMMENTS}

The student sample was of 26. For each question in the inquiry, the student had to select the adequate grade from very poor (1) to excellent (7). A seven level choice was used considering the knowledge level of respondents. With a higher discretization the results have a higher scattering and so they include richer information. The percentage of good (5), very good (6) and excellent (7) answers will be considered together and used as an indication of the evaluation level. In the present a short evaluation is considered and rates over $75 \%$ will be taken as very positive indicators. The ten selected answers presented here are due to their awareness in the scope of remote labs. They are summarized in Table 1 . The students were also strongly encouraged to formulate free comments. The technical constrains are the most popular, although some others were also added in a very gratifying way for the authors and their work teams and labs.

It was also found that the assessment component related with remote labs, based in reports elaborated by students, presented an average increase of $10 \%$ when compared with the result from the old written component on sensor reports. The authors believe that the remote hands-on activity, the related exploitation of concepts by observing them in practice, the enthusiasm for using the technology, the contact with experimental facilities and people from other different university, the prompt help either from their teacher in Coimbra University or from people at Porto University, encouraged them and increased the interest of the students. 
TABLE I.

ANALYSIS OF SOME QUESTIONS

\begin{tabular}{|l|c|}
\hline \multicolumn{1}{|c|}{ Question } & $\begin{array}{c}\text { (good + } \\
\text { very good + } \\
\text { excellent) } \\
\text { \% }\end{array}$ \\
\hline Acquisition of new knowledge/concepts & 80.7 \\
\hline Deeper learning & 80.7 \\
\hline Understanding of the related theory & 69.2 \\
\hline Contribution for learning autonomy & 76.9 \\
\hline Contribution for better learning quality & 76.9 \\
\hline Development of professional skills & 57,7 \\
\hline Relevance of the collaborative activity in remote labs & 80,8 \\
\hline $\begin{array}{l}\text { Did collaborative work exist between students in } \\
\text { remote labs? }\end{array}$ & 76,9 \\
\hline $\begin{array}{l}\text { Are the results of remote experiments clear according } \\
\text { to the related knowledge? }\end{array}$ & 88,5 \\
\hline Evaluation of the remote experiments & 76,9 \\
\hline
\end{tabular}

Free comments

Some comments were related with technical constrains such as:

- the slot time duration for each experiment;

- $\quad$ the browser imposed by the used software;

- $\quad$ the firewall problems;

- $\quad$ The relevance of the system real scale (the need of incorporating a universal object as a reference).

But other comments were really enthusiastic and as follows:

- Carry-on with this important work!

- An initiative to be followed by other universities;

- The reduced interaction between the user and all the equipment can be not so impressive. But, the possibility of accessing the experiments from anywhere, anytime, is a big step!

- Many problems were promptly solved by the FEUP team;

- The teacher was always alert and helpful.

\section{FINAL COMMENTS}

The authors consider these results as very positive giving confidence for other future explorations. The authors believe in its complementary contribution for the Universities, their staff and students. Intensifying collaborations as this one will foster other additional cooperation, which could bring unquestionable advantages for the development of many other works either related with higher education or in the R\&D\&I fields.

\section{ACKNOWLEDGMENT}

A special mention should be addressed to the Laboratory of Instrumentation for Measurement (LIM) team at FEUP.

\section{REFERENCES}

[1] M.T. Restivo, J.C. Marques and T. Vieira, "Experimenta@FEUP,” in Proc. of the International Conference on Engineering Education, ICEE 2007, Coimbra, Portugal, 2007.
[2] M.T. Restivo, F.G. Almeida, M.F. Chouzal, J. Mendes, A.M. Lopes, "Measurement: concepts, methods and practice within an electronic book," Acta Electrotechnica et Informatica, vol.8, No.2, 2009.

[3] G. Eason, B. Noble, and I. N. Sneddon, "On certain integrals of Lipschitz-Hankel type involving products of Bessel functions," Phil. Trans. Roy. Soc. London, vol. A247, pp. 529-551, April 1955.

[4] S. Leitão, T. Restivo, E. Carrapatoso, "Remotely Accessed Experimental Systems," in Proc. of the International Conference on Remote Engineering and Virtual Instrumentation REV2007, Portugal, 2007.

[5] F.G. Almeida, M.F. Chouzal, J. Mendes, A.M. Lopes, "Laboratories of Instrumentation for Measurement/Laboratórios de Instrumentação para Medição," bilingual version, Ed. UPorto, March 2008.

[6] M. C. Gameiro da Silva, "Software tools to support teaching of signal processing and filtering in a course about measurement systems," in Proc. of the 5th International Conference on Mechanics and Materials in Design, 24-26 July 2006, Porto, Portugal.

[7] M. C. Gameiro da Silva, "Enhancement of teaching about measurement systems in a graduation course on mechanical engineering," in Proc. of the 5th International Conference on Mechanics and Materials in Design, 24-26 July 2006, Porto, Portugal

[8] M. C. Gameiro da Silva, "Sound Measuring Virtual Instruments," in Proc. of the 4th International Conference on Remote Engineering and Virtual Instrumentation, 25-27 June 2007, Porto, Portugal.

[9] M. C. Gameiro da Silva, M.L.O.S. Mateus, "Desenvolvimento de um conjunto de aplicações computacionais para emulação de equipamentos de medição e análise sonora,” in Proc. V Congresso Ibérico de Acústica, Accoustics European Symposium, 20-22 October 2008, Coimbra, Portugal

[10] M.T. Restivo, F.G. Almeida, M.F. Chouzal, J. Mendes, A.M. Lopes, "Laboratories of Instrumentation for Measurement, New ebook Description,” Sensors \& Transducers, Vol.100, Issue 1, January 2009, pp.161-164, 2009.

[11] C. Dorninger, "Encouraging innovative virtual learning environments in technical education," in Proceedings of 38th IGIP Symposium $-Q^{2}$ of $E^{2}$ Quality and Quantity of Engineering Education, 6-9 September 2009, Graz, Austria, 2009.

[12] A. Pester, M.E. Auer, D.G. Zutin, “A Europian Master Programme in Remote Engineering," in Proc. of 38th IGIP Symposium $-Q^{2}$ of $E^{2}$ Quality and Quantity of Engineering Education, 6-9 September 2009, Graz, Austria, 2009.

[13] C. Samoila, S.G. Cosh, D. Ursutiu, "Competences, Remote Labs and Bologna Process," Advances on remote laboratories and elearning experiences, University of Dueno, pp.63-96, 2007.

\section{AUTHORS}

Maria Teresa Restivo is with the Department of Mechanical Engineering of Faculdade de Engenharia da Universidade do Porto (e-mail: trestivo@fe.up.pt).

Manuel Gameiro da Silva is with the Department of Mechanical Engineering of University of Coimbra (email: manuel.gameiro@dem.uc.pt)

The publication of this work was financially supported by the Unit of System Integration and Process Automation (UISPA), within the Institute of Mechanical Engineering (IDMEC) at the Faculdade de Engenharia da Universidade do Porto (FEUP).

This article was modified from a presentation at the IRF'2009 conference in Porto, Portugal, July 2009. Submitted 08 October 2009. Published as resubmitted by the authors on 20 October 2009. 